\title{
Expression of tesmin (MTL5) in non-small cell lung cancer: A preliminary study
}

\author{
JEDRZEJ GRZEGRZOLKA ${ }^{1}$, AGNIESZKA GOMULKIEWICZ ${ }^{1}$, MATEUSZ OLBROMSKI ${ }^{1}$, \\ NATALIA GLATZEL-PLUCINSKA ${ }^{1}$, ALEKSANDRA PIOTROWSKA ${ }^{1}$, KATARZYNA RATAJCZAK-WIELGOMAS ${ }^{1}$, \\ ADAM RZECHONEK ${ }^{2}$, MARZENA PODHORSKA-OKOLOW ${ }^{1,3}$, ZBIGNIEW KRAWCZUK $^{4}$ and PIOTR DZIEGIEL ${ }^{1,5}$
}

\author{
Departments of ${ }^{1}$ Histology and Embryology, and ${ }^{2}$ Thoracic Surgery, ${ }^{3}$ Division of Ultrastructure Research, \\ Wroclaw Medical University, 50-368 Wroclaw; ${ }^{4}$ Department of General Surgery, Poviat Hospital Complex in Olesnica, \\ 56-400 Olesnica; ${ }^{5}$ Department of Physiotherapy, University School of Physical Education, 51-612 Wroclaw, Poland
}

Received September 16, 2018; Accepted April 16, 2019

DOI: $10.3892 /$ or.2019.7145

\begin{abstract}
Lung cancer is the most commonly diagnosed cancer and the most frequent cause of death worldwide. Tesmin (testis-specific metallothionein-like protein; MTL-5) is a 60-kDa protein which has cysteine-rich motifs (CXC domain), characteristic of metallothioneins (MTs). Tesmin expression has been observed in germ cells during spermatogenesis, oogenesis and also in various cell nuclei after exposure to heavy metal ions. Yet, the role of tesmin in carcinogenesis is unknown. The aim of the present study was to evaluate the localization and intensity of tesmin expression in non-small cell lung cancer (NSCLC) and its association with the clinicopathological data of patients. A total of 121 cases of NSCLC and 20 cases of non-cancerous tissue samples from the surgical margin (control) were used for immunohistochemistry (IHC). In addition, 20 cases of frozen NSCLC tissues and 20 cases of control were used for the in vivo study. Normal lung fibroblasts (IMR-90) and lung cancer cell lines NCI-H1703 (lung squamous cell carcinoma), NCI-H522 and A549 (both adenocarcinomas of the lung) were used for western blot analysis (WB) and RT-PCR studies. Positive cytoplasmic tesmin expression was observed in $88.42 \%$ of the examined cases of NSCLC. Statistical analysis showed increased IHC tesmin expression in cancer cells compared to that noted in the controls. In addition, MTL5 mRNA and WB tesmin protein expression were also higher in cancer cases compared to the controls. A positive correlation between tesmin and Ki-67 IHC expression was demonstrated $(\mathrm{r}=0.32 ; \mathrm{P}<0.001)$. Higher WB tesmin expression was also associated with shorter overall survival $(\mathrm{P}<0.05$, Mantel-Cox test). The in vitro study revealed
\end{abstract}

Correspondence to: Mr. Jedrzej Grzegrzolka, Department of Histology and Embryology, Wroclaw Medical University, Chalubinskiego 6a, 50-368 Wroclaw, Poland

E-mail: jedrzej.grzegrzolka@gmail.com

Key words: NSCLC, non-small cell lung cancer, lung cancer, tesmin, MTL5 higher tesmin protein (WB) and MTL5 (qPCR) in lung cancer cell lines compared to the lung fibroblast control cell line. Higher tesmin expression in cancer cells compared to control cells may suggest a role of tesmin in NSCLC carcinogenesis. A positive correlation between tesmin and $\mathrm{Ki}-67$ could indicate a possible role of tesmin in the proliferation of NSCLC.

\section{Introduction}

In terms of incidence and mortality rates, lung cancer is the most commonly diagnosed cancer and is the most frequent cause of death worldwide (1). Males are affected by lung cancer twice more frequently than females. However, a more dynamic increase in the incidence is observed in females. The peak incidence of lung cancer is observed after 50 years of age with more than $50 \%$ of cases $>65$ years of age (2). Lung cancers are classified as small cell $(\sim 17 \%)$ and non-small cell lung cancers (NSCLC), which account for $\sim 80 \%$ of all lung cancer cases. There are three basic histological subtypes of NSCLC, i.e. squamous cell carcinoma, adenocarcinoma and large cell carcinoma which account for $90 \%$ of all diagnosed cases of NSCLC (3). Factors which are directly linked to the course and prognosis of lung cancer are the following: Histological type of cancer, pTNM staging system, and presence of the EGFR gene mutation and EML4-ALK fusion gene (4).

All proteins from the metallothionein (MT) family are characterized by the ability to bind heavy metal ions such as zinc, copper, mercury, lead or cadmium. These proteins bind free ions of the above metals into inactive complexes, thus, playing a key role in protecting cells from the negative effects of heavy metals (5). Apart from the detoxification function, MTs are also involved in maintaining homeostasis of metal ions essential for proper functioning of the organism. Reversible binding of zinc ions leads to the influence of MTs on the activity of numerous enzymes and transcription factors dependent on the presence of the above ions. These enzymes and transcription factors are responsible for intracellular processes such as DNA replication, transcription, translation and the processes of proliferation, differentiation and cell apoptosis $(6,7)$. Moreover, MTs demonstrate strong antioxidant 
properties due to their cysteine-rich peptide structure. MTs constitute one of the main elements of cell protection against reactive oxygen species next to glutathione (GSH) and antioxidant enzymes [superoxide dismutase (SOD), catalase (CAT) and glutathione peroxidase $(\mathrm{GPx})](8,9)$. It has been postulated that the role of MTs in carcinogenesis and cancer progression may be related to the regulation of proliferation processes and cell differentiation (10-13). MTs serve as a direct reservoir of zinc ions indispensable for the processes of the biosyntheses of nucleic acids and proteins which occur intensively in cancer cells undergoing mitosis. This is confirmed not only by an increased MT level in the area of hyperplasia but also by translocation of protein from the cytoplasm to the cell nucleus in the DNA synthesis phase (S-phase) observed in cancer cells in vitro (12-14). Moreover, it has also been demonstrated that MTs can increase the proliferative potential of cancer cells through the interaction with $\mathrm{p} 53$ protein and inhibition of apoptosis $(15,16)$. Involvement of MTs in the development of cancer cell resistance to chemotherapy and radiotherapy is also a significant issue related to cancer. This phenomenon is most probably related to antioxidant properties of these proteins $(8,17)$.

Testis-specific metallothionein-like protein, tesmin, is also known as metallothionein-like 5 protein, testis-specific MTL-5, or CXC domain containing protein 2. It is a $60-\mathrm{kDa}$ protein which has cysteine-rich motifs (CXC domain), characteristic of MTs. These domains are located between amino acids 161-175 and 173-188 of the peptide sequence of tesmin (18). In humans, the locus for the tesmin gene is on $11 q 13.3$ (19). The specific characteristics of this protein are shown in Table I.

The presence of tesmin has been confirmed in many species of plants and animal cells. Tesmin was firstly described in mouse testicular tissue on day 8 of postnatal development which coincided with the entry of germ cells into meiosis (20). This was confirmed by other authors who observed the occurrence of tesmin expression at the stage of meiotic prophase I, during the division of male and female germ cells of rats (21). Therefore, a hypothesis on the probable use of tesmin as a specific marker for germ cell differentiation was proposed. Moreover, this protein is mainly found in the cytoplasm of spermatocytes and is translocated to the nucleus during the $\mathrm{G} 2 / \mathrm{M}$ phase of meiotic division $(17,22)$, which may be indicative of the role of tesmin in the regulation of other genes responsible for spermatogenesis. However, lack of tesmin expression in organized chromosomes during meiosis can suggest that this protein is not permanently bound to chromatin (18).

Nuclear expression of tesmin can be, as in the case of MTs, a response to stress related to the presence of high concentrations of heavy metal ions. In in vitro studies, the occurrence of the above localization of tesmin expression was observed after experimental stimulation of a COS- 1 cell culture (fibroblast cell line from the kidney of African green monkey) using cadmium chloride and zinc chloride (22). This observation was confirmed in an in vivo experiment using immunohistochemical and immunofluorescence methods to study the localization of tesmin expression in the testicular tissue of mice which had previously been given an intravenous cadmium solution (22). The change in tesmin localization due to the cadmium solution was found to be related to the occurrence of features of apoptosis in mouse testicular cells (22). A similar phenomenon was observed in rats in which tesmin expression was also increased both in the cytoplasm and nucleus of the spermatogonium as the result of zinc supplementation (23).

Expression of tesmin mRNA was noted in mouse embryonic ovaries and testes, embryonic renal tissue, brain, liver, heart and mature myocardial tissue. This may indicate that this protein is not specific to germ cells only $(21,24)$.

It has also been postulated that tesmin can be a coactivator for nuclear mineralocorticoid (aldosterone and deoxycorticosterone) receptor, which is a ligand-dependent transcription factor (24). This observation was not confirmed in the case of cortisol which also displays an insignificant mineralocorticoid activity (24).

To date, the expression of tesmin in adult humans has been observed only in gastric carcinoma and prostate cancer $(25,26)$. Decreased expression of tesmin mRNA was associated with the single nucleotide polymorphism phenomenon and the presence of risk alleles of genes promoting the development of prostate cancer (27). In addition, online databases contain information about the high expression of tesmin mRNA in various cancer cell lines (Figs. S1-S3).

The aim of the present study was to examine the expression of tesmin in NSCLC cases and its association with the clinicopathological data.

\section{Materials and methods}

Patients. An immunohistochemical (IHC) study was performed on 121 paraffin blocks from patients diagnosed with NSCLC and treated between February 1998 and November 2010 at the Department and Clinic of Thoracic Surgery of Wroclaw Medical University (Wroclaw, Poland). In addition, we used 20 paraffin blocks with tissue samples from the resection margin of patients with NSCLC as a control. All patients were treated surgically and tissue specimens were prepared prior to chemotherapy. To evaluate the histopathological subtype of NSCLC we used anti-p63 (for lung squamous cell carcinoma) and TTF-1 (for adenocarcinoma) IHC reactions. Patients from the IHC group were followed up for $32.76 \pm 40.55$ months (median, 17.0; range, 0.5-145 months). During this period 64 patients succumbed to the disease. However, 19 patients were lost to follow-up. The experiment was performed in accordance with the ethical standards and following approval of the Ethics Committee of Wroclaw Medical University (decision no. KB 455/2009 and KB 40/2017) and all patients provided a written statement of informed consent for the use of the material samples for scientific research.

Additionally, we used 20 tissue samples from NSCLC cases quick frozen in liquid nitrogen and paired 20 control lung tissue samples from the surgical margin of these patients. Patients from the RT-PCR and WB groups were followed up for 47.89 \pm 25.59 months (median, 63.98; range, 2-72 months). Nine patients died during the follow-up. However, none of the patients were lost to follow-up.

The demographic and clinicopathological characteristics of the patients are presented in Table II. 
Table I. Differences in the characteristics between tesmin protein and metallothioneins $(18,19,25)$.

\begin{tabular}{lcc}
\hline Characteristics & Tesmin & Metallothioneins \\
\hline Number of known isoforms & I-III & I-IV \\
Molecular weight & $27 ; 32$ or $60 \mathrm{kDa}$ & $6-7 \mathrm{kDa}$ \\
Gene locus & $11 \mathrm{q} 13.3$ & $16 \mathrm{q} 13$ \\
Number of coding exons & 9 & 3 \\
Presence of aromatic acids & Present & Absent \\
Promoter regions-dependent on the presence of metals and the TATA box & Absent & Present \\
\hline
\end{tabular}

Table II. NSCLC cases and tumor characteristics.

\begin{tabular}{|c|c|c|}
\hline Parameters & IHC $(n=121)$ & WB/RT-PCR $(n=20)$ \\
\hline Mean age (range) & $62.36 \pm 8.68(39-87)$ & $64.65 \pm 15.28(52-76)$ \\
\hline \multicolumn{3}{|l|}{ Sex, n $(\%)$} \\
\hline Male & $95(78.51)$ & $14(70)$ \\
\hline Female & $26(21.49)$ & $6(30)$ \\
\hline \multicolumn{3}{|l|}{ Tumor size, n (\%) } \\
\hline $\mathrm{T} 1$ & $32(26.45)$ & $9(45)$ \\
\hline $\mathrm{T} 2$ & $65(53.72)$ & $8(40)$ \\
\hline $\mathrm{T} 3$ & $11(9.09)$ & $3(15)$ \\
\hline $\mathrm{T} 4$ & $13(10.74)$ & $0 \quad(0)$ \\
\hline \multicolumn{3}{|c|}{ Lymph node involvement, $\mathrm{n}(\%)$} \\
\hline No & $54(44.63)$ & $15(75)$ \\
\hline $\mathrm{N} 1, \mathrm{~N} 2, \mathrm{~N} 3$ & $67(55.37)$ & $5(25)$ \\
\hline \multicolumn{3}{|l|}{ Grade, n (\%) } \\
\hline G1 & $9 \quad(7.44)$ & $0 \quad(0)$ \\
\hline $\mathrm{G} 2$ & $78(64.46)$ & $13(65)$ \\
\hline G3 & $32(26.45)$ & $6(30)$ \\
\hline No data, n (\%) & $2(1.65)$ & $1(5)$ \\
\hline \multicolumn{3}{|l|}{ pTNM, n (\%) } \\
\hline I & $45(37.19)$ & $10(50)$ \\
\hline II & $23(19.01)$ & $7(35)$ \\
\hline III & $49(40.50)$ & $3(15)$ \\
\hline IV & $4 \quad(3.31)$ & $0 \quad(0)$ \\
\hline \multicolumn{3}{|l|}{ Stage, n (\%) } \\
\hline Early & $68(56.20)$ & $17(85)$ \\
\hline Advanced & $53(43.80)$ & $3(15)$ \\
\hline \multicolumn{3}{|l|}{ Histology, n (\%) } \\
\hline Adeno & $60(49.59)$ & $10(50)$ \\
\hline Plano & $55(45.45)$ & $9(45)$ \\
\hline Mixed & $6 \quad(4.96)$ & $1 \quad(5)$ \\
\hline \multicolumn{3}{|l|}{ Tesmin IHC, n (\%) } \\
\hline 0 & 14 (11.57) & - \\
\hline $1-12$ & $107(88.43)$ & - \\
\hline
\end{tabular}

NSCLC, non-small cell lung carcinoma; IHC, immunohistochemistry.

Immunohistochemistry. The paraffin blocks with NSCLC cases were cut into $4-\mu \mathrm{m}$ sections. The immunohistochemical reactions were performed using anti-tesmin rabbit polyclonal antibody (cat. no. NBP2-13624; Novus Biologicals, LLC, 
Littleton, Centennial, CO, USA) in a 1:400 dilution and anti-Ki-67 mouse monoclonal antibody, Clone MIB-1 (Dako, Glostrup, Denmark) ready-to-use. Immunohistochemical reactions were performed using Dako Autostainer Link 48 (Dako). Visualization of the reactions was carried out using EnVision $^{\mathrm{TM}}$ FLEX High pH (Link) reagents (Dako), according to the manufacturer's instructions. Positive IHC reaction for tesmin antigen was assessed using the immunoreactive scale (IRS) by Remmele and Stegner (28). This scale evaluates the percentage of positive cancer cells (A) and their intensity of color reaction (B). The final result is a product of these two values (AxB; Table III). Before the IHC experiments, according to the antibody manufacturer's instructions, we performed reactions to the positive and negative controls (Fig. S4A and B).

Additionally, nuclear expression intensity for Ki-67 antigen was determined using a scale analyzing the percentage of the number of cancer cells demonstrating nuclear expression of the studied antigen, according to the following scale: $0 \%-0 \mathrm{p}$., $1-10 \%-1$ p., $11-25 \%$-2p., 26-50\% -3p., 51-100\% -4p. All specimens were assessed using an Olympus BX-41 light microscope (Olympus Corp., Tokyo, Japan). Moreover, p63 and TTF-1 antigen expression was used to confirm the histological type of the tumor [TTF-1 (+), adenocarcinoma; p63 (+), squamous cell carcinoma].

Cell lines. Normal lung fibroblasts (IMR-90) and the lung cancer cell lines NCI-H1703 (lung squamous cell carcinoma), NCI-H522 (adenocarcinoma of the lung) and A549 (adenocarcinoma of the lung) were obtained from the American Type Culture Collection (ATCC; Manassas, VA, USA). The following cell culture media were used: minimum essential medium (MEM) supplemented with non-essential amino acids for the IMR90 cell line, RPMI-1640 for the NCI-H1703 and NCI-H522 cell line and high-glucose Dulbecco's modified Eagle's medium for the A549 cell line. All of the media were additionally supplemented with L-glutamine to a final concentration of $2 \mathrm{mM}$, and with fetal bovine serum (FBS) to a final concentration of $10 \%$. All of the cell culture media and reagents were provided by Sigma-Aldrich (Merck KGaA, Darmstadt, Germany). In addition, we performed in vitro knockdown experiments on the NCI-H1703 NSCLC cell line using Tesmin Silencer siRNA s18519 and s18520 (Thermo Fisher Scientific, Inc., Waltham, MA, USA), receiving the silencing of the tesmin expression at the height of $\sim 55 \mathrm{kDa}$ (Fig. S4C).

Real-time PCR ( $q P C R$ ). The mRNA expression of MTL5 was analyzed using 20 cases of NSCLC [10 cases of adenocarcinoma (AC) and 10 cases of squamous cell carcinoma (SCC)], 20 cases of control as well as cell cultures (NCI-H1703, A549, NCI-H522 and IMR90). Total RNA was extracted from the studied tissues and cell lines with RNeasy Mini kit (Qiagen, Hilden, Germany) according to the manufacturer's protocol. To eliminate genomic DNA contamination, on-column DNase digestion was performed using RNase-Free DNase Set (Qiagen). The concentration and quality of RNA samples were assessed by spectrophotometry using NanoDrop 1000 (NanoDrop Technologies; Thermo Fisher Scientific, Inc.). First-strand cDNA was synthesized with the High-Capacity
Table III. The assessment scale of immunohistochemical specimens, according to Remmele and Stegner (28).

\begin{tabular}{lll}
\hline $\begin{array}{l}\text { Number of } \\
\text { points }\end{array}$ & \multicolumn{1}{c}{$\begin{array}{c}\text { Intensity of } \\
\text { color reaction }\end{array}$} & $\begin{array}{l}\text { Percentage of } \\
\text { reacting cells }\end{array}$ \\
\hline 0 & No reaction & $0 \%$ \\
1 & Weak reaction & $<10 \%$ \\
2 & Moderate reaction & $10-50 \%$ \\
3 & Strong reaction & $51-80 \%$ \\
4 & - & $81-100 \%$ \\
\hline
\end{tabular}

cDNA Reverse Transcription kit (Applied Biosystems; Thermo Fisher Scientific, Inc.). The real-time PCR was performed using 7900HT Fast Real-Time PCR System and TaqMan Gene Expression Master Mix (Applied Biosystems; Thermo Fisher Scientific, Inc.). $\beta$-actin (ACTB) was used as an endogenous control. The following sets of primers and TaqMan probes were used in the studies: Hs01127481_m1 for MTL5 and Hs99999903_m1 for ACTB (Applied Biosystems; Thermo Fisher Scientific, Inc). The reactions were conducted in triplicates under the following conditions: Polymerase activation at $50^{\circ} \mathrm{C}$ for $2 \mathrm{~min}$, denaturation at $94^{\circ} \mathrm{C}$ for $10 \mathrm{~min}$ followed by 40 cycles of denaturation at $94^{\circ} \mathrm{C}$ for $15 \mathrm{sec}$ and annealing with synthesis at $60^{\circ} \mathrm{C}$ for $1 \mathrm{~min}$. The relative expression of MTL5 mRNA was calculated using the $\Delta \Delta \mathrm{Cq}$ method (29).

Protein isolation, SDS-PAGE and western blot analysis. Western blot technique was used to determine tesmin expression levels in fresh frozen tissues from 20 NSCLC cases (10 AC and 10 SCC), 20 control cases and cell cultures (NCI-H1703, A549, NCI-H522 and IMR90). Whole protein lysates from the tissue samples were obtained using T-PER Tissue Protein Extraction reagent (Thermo Fisher Scientific, Inc.) with the addition of Halt ${ }^{\mathrm{TM}}$ Protease Inhibitor Cocktail (Thermo Fisher Scientific, Inc.) and 0.2 mM PMSF (Sigma-Aldrich; Merck $\mathrm{KGaA}$ ). Protein concentrations were quantified using the Pierce BCA Protein Assay kit (Thermo Fisher Scientific, Inc.) and NanoDrop $^{\text {TM }} 1000$ (NanoDrop Technologies; Thermo Fisher Scientific, Inc.) spectrophotometer. Equal amounts of total protein $(30 \mu \mathrm{g})$ were mixed with Laemmli sample buffer and resolved on $10 \%$ acrylamide gel by SDS-PAGE (30). After the electrophoresis, the samples were transferred to Immobilon-P polyvinylidene difluoride (PVDF) membranes (Merck KGaA) in the XCell SureLock ${ }^{\mathrm{TM}}$ Mini-Cell Electrophoresis System (Thermo Fisher Scientific, Inc.). Next, the membranes were blocked in $4 \%$ bovine serum albumin (BSA; Merck KGaA) solution in TBST buffer (0.2 $\mathrm{M}$ Tris, $1.5 \mathrm{M} \mathrm{NaCl}$ and $0.1 \%$ Tween-20). After blocking, the membranes were incubated overnight at $4^{\circ} \mathrm{C}$ with the primary rabbit anti-human tesmin polyclonal antibody (cat. no. NBP2-13624; Novus Biologicals), diluted at 1:200. Furthermore, the membranes were incubated with the secondary HRP-conjugated donkey anti-rabbit antibody (cat. no. 715-035-152; Jackson ImmunoResearch Laboratories, West Grove, PA, USA), diluted at 1:3,000 for $1 \mathrm{~h}$ at room temperature. Finally, the membranes were rinsed and treated with the Luminata Classico (Merck KGaA) 

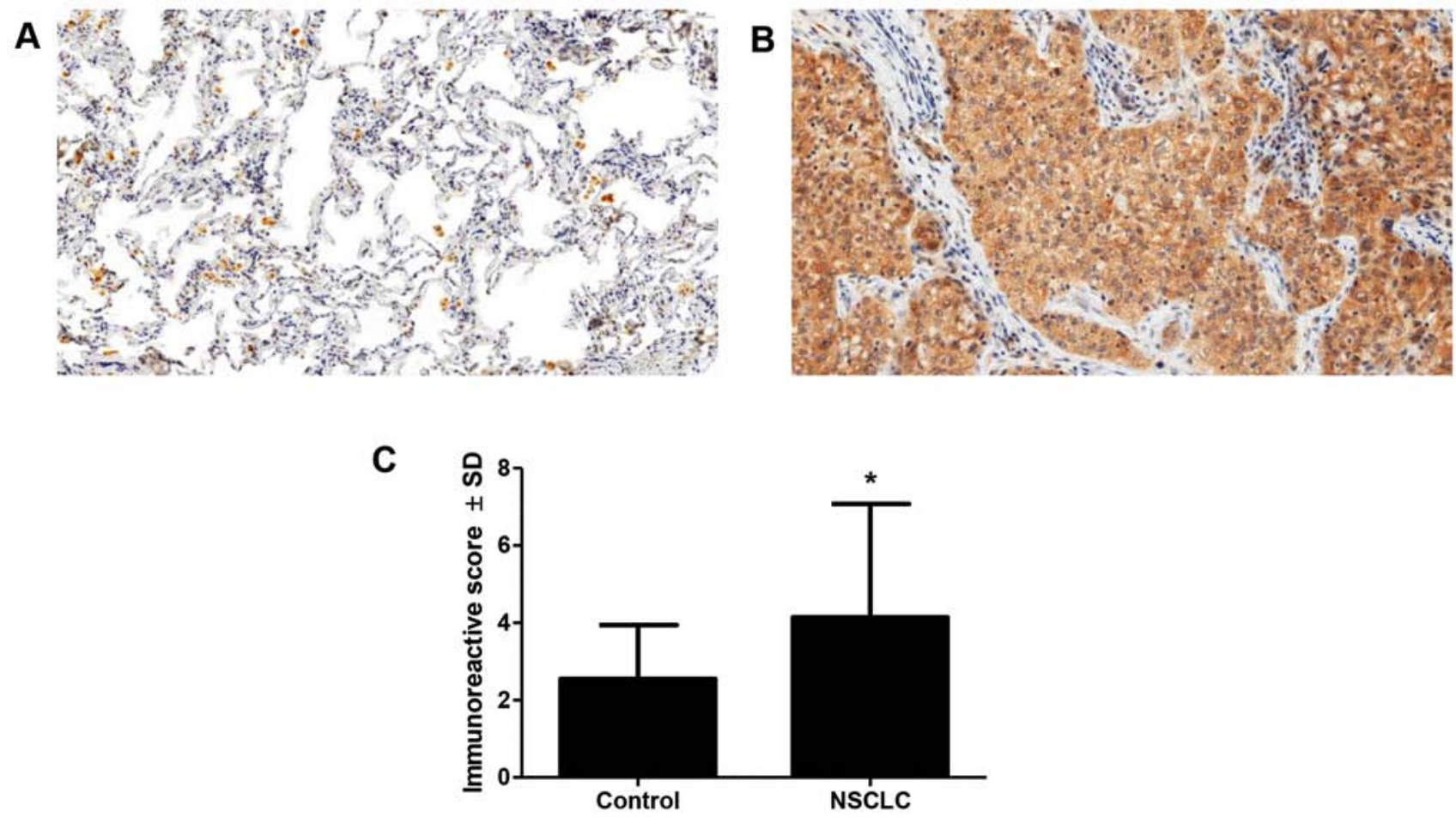

Figure 1. Immunohistochemical (IHC) evaluation of tesmin protein expression in macrophages of pulmonary alveoli in (A) non-malignant lung tissue and (B) NSCLC. Magnification, x200. (C) Statistical analysis revealed significant higher tesmin expression as assessed by the immunoreactive score in cancer cells compared to control non-malignant lung tissue. ${ }^{*} \mathrm{P}<0.05$, compared to the control. NSCLC, non-small cell lung cancer.

chemiluminescent substrate. The reactions were visualized using the ChemiDoc Imaging system (Bio-Rad Laboratories, Hercules, CA, USA). $\beta$-actin detected with primary rabbit anti-human $\beta$-actin antibody (cat. no. 4970; Cell Signaling Technology, Leiden, The Netherlands) diluted at 1:1,000 and secondary HRP-conjugated donkey anti-rabbit antibody (cat. no. 711-035-152; Jackson ImmunoResearch Laboratories) diluted at 1:3,000 were used as an internal control to normalize the amount of tesmin. Densitometric analysis of obtained results was performed with the use of Image Lab 6.0.1 software (Bio-Rad Laboratories).

Immunofluorescence (IF). Cells were fixed with $4 \%$ paraformaldehyde for $12 \mathrm{~min}$ at room temperature (RT) and permeabilized using $0.2 \%$ Triton $\mathrm{X}-100$ for $10 \mathrm{~min}$. The cells were incubated overnight at $4^{\circ} \mathrm{C}$ with primary anti-tesmin antibodies (cat. no. NBP2-13624; dilution 1:200; Novus Biologicals). Subsequently, secondary fluorescein isothiocyanate (FITC)-conjugated anti-rabbit antibodies were applied (dilution 1:1,000; for $1 \mathrm{~h}$ at RT; Jacksons Immunoresearch Laboratories, Ely, Cambridgeshire, UK). The sections were mounted in a DAPI-containing medium (ProLong Gold Antifade reagent with DAPI) (Thermo Fisher Scientific, Inc.) and analyzed using a confocal laser scanning microscope FV3000 Fluoview (Olympus Corp.). Omitting the addition of primary antibody was performed as the respective negative controls.

Statistical analysis of the obtained results. The Shapiro-Wilk test was used to evaluate the normality assumption of the examined groups. The Mann-Whitney or Wilcoxon tests were used to compare the differences in the expression of examined markers in all groups of patients and the clinicopathological data. Additionally, the Spearman's correlation test was used to analyze the existing correlations. The Kaplan-Meier method was used to construct survival curves. The Mantel-Cox method was performed to evaluate the analysis of survival. Additionally, the Kaplan-Meier plotter web-based tool was used to draw Kaplan-Meier curves and to analyze patient survival with high and low expression of MTL5 mRNA (31). All statistical analyses were performed using GraphPad Prism 5.0 (GraphPad Software, Inc., La Jolla, CA, USA). The results were considered statistically significant at $\mathrm{P}<0.05$.

\section{Results}

IHC. Expression of tesmin was observed in the cytoplasm and nuclei of cancer cells. In addition, there was also cytoplasmic expression noted in inflammatory cells and alveolar macrophages (Fig. 1A and B). Diverse positive cytoplasmic expression of tesmin was observed in 107 (88.42\%) of cases, positive nuclear expression in $36(27.75 \%)$ cases and positive low expression in all control cases. Statistical analysis revealed significantly higher expression of tesmin in cancer cases compared to that noted in the control (Fig. 1C). Furthermore, we observed significantly higher expression of tesmin in pT4 compared to pT1-3 cases $(3.79 \pm 2.95$ vs. 6.23 \pm 1.96 ; $\mathrm{P}<0.01$, Mann-Whitney test; data not shown). We did not reveal any associations between tesmin expression and $\mathrm{G}, \mathrm{pN}$, stage and sex of the patients. Additionally, there was a medium positive correlation between expression of tesmin and Ki-67 ( $\mathrm{r}=0.32, \mathrm{P}<0.001$, Spearman correlation test; Fig. 2A-E). 

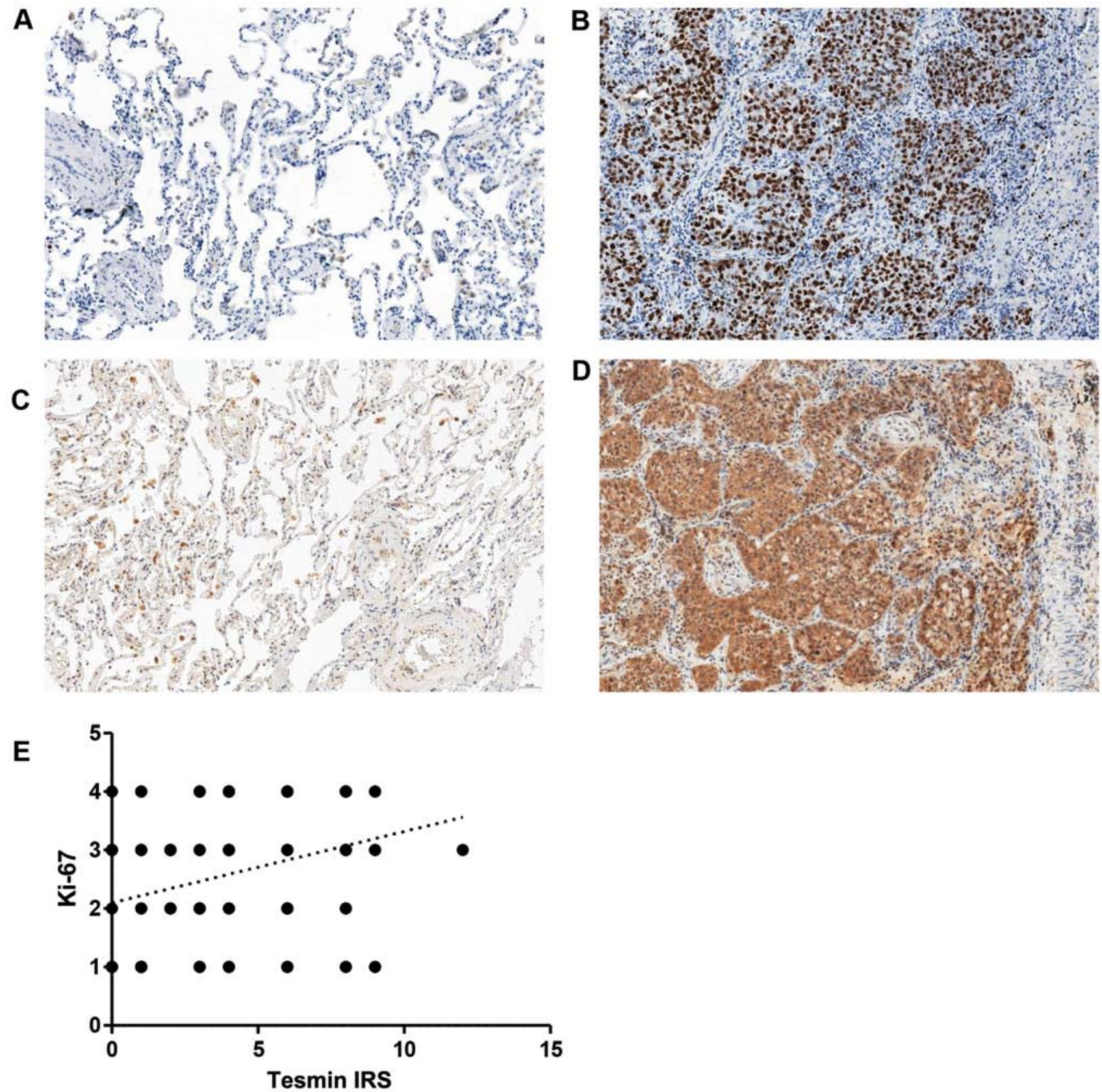

Figure 2. Immunohistochemical expression of Ki-67 in (A) control non-malignant lung tissue and (B) cancer. Tesmin expression in (C) control non-malignant lung tissue and (D) cancer. (E) Correlation of IHC expression of tesmin (cytoplasmic) and Ki-67 (nuclear) in NSCLC cancer cells ( $\mathrm{r}=0.3201$; P $<0.001$; Spearman's correlation test). Magnification, x200. IRS, immunoreactive score.

$q P C R$. The results of qPCR analysis of MTL5 gene expression in vivo showed significantly higher expression of MTL5 in NSCLC compared to that noted in the non-cancerous tissue from the resection margin $(\mathrm{P}<0.05$, paired t-test) (Fig. 3A). The MLT5 expression was also higher in non-small cell lung cancer cell lines (NCI-H1703, A549 and NCI-H522) compared to that noted in the lung fibroblast culture (IMR90) in the in vitro experiment (Fig. 3B).

Western blot analysis. Densitometric analysis of tesmin expression (WB) showed a significantly higher level of tesmin protein $(70 \mathrm{kDa})$ in the cancer than that in the adjacent lung tissues ( $\mathrm{P}<0.0001$, paired t-test; Fig. $4 \mathrm{~A}$ and $\mathrm{B})$. In vitro analysis of tesmin expression in cell lines showed that the presence of tesmin protein in nuclear fraction of cell lysate was higher in non-small cell lung cancer cell lines (NCI-H1703, A549 and NCI-H522) compared to the lung fibroblast culture (IMR90) (Fig. 4C and D).

$I F$. To verify localization of tesmin expression, IF was performed on lung cancer cell lines. The analysis of the results of these in vitro studies revealed cytoplasmic and nuclear positive IF expression of tesmin corresponding to the results of our IHC studies (Fig. 5).

Analysis of survival. Analysis of survival revealed that higher IHC expression of tesmin was associated with shorter survival (trend did not reach statistical significance; 
A

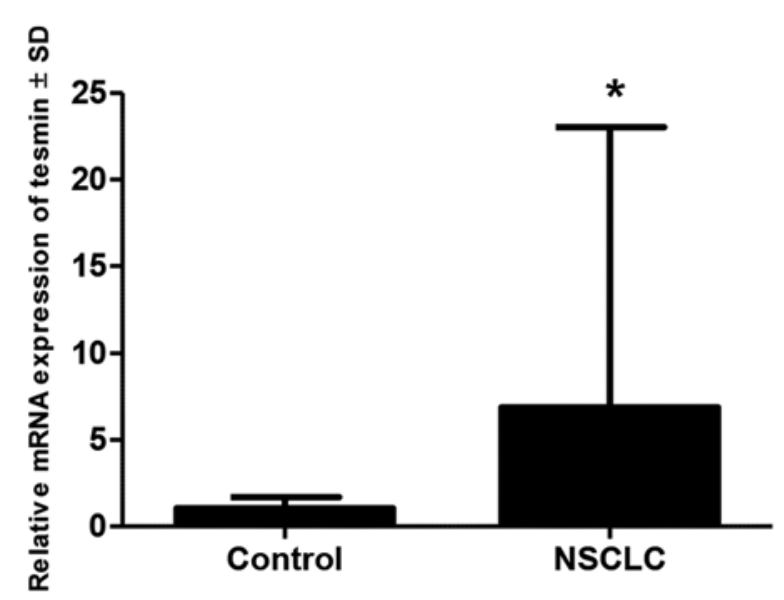

B

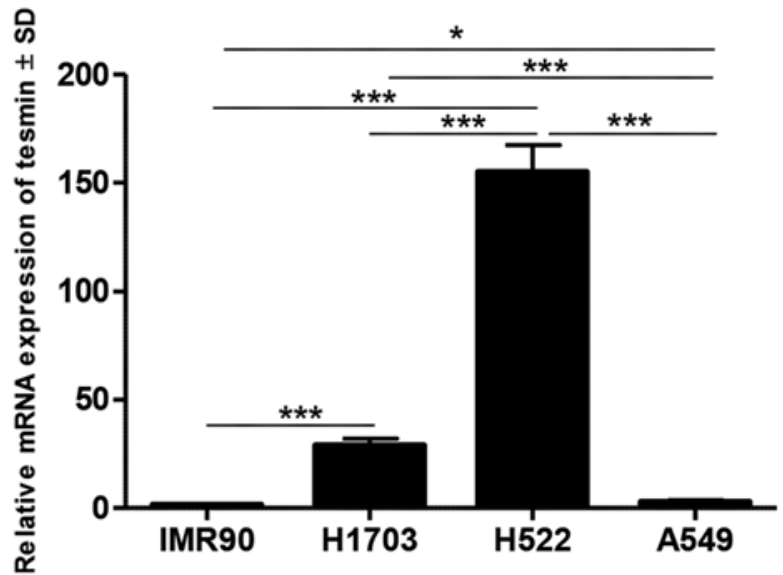

Figure 3. (A) Higher expression of MTL5 mRNA was demonstrated in NSCLC specimens compared to that noted in the paired non-malignant lung tissue specimens used as a control obtained by qPCR analysis. (B) Higher expression of MTL5 mRNA was demonstrated in non-small cell lung cancer cell lines (NCI-H1703, A549 and NCI-H522) compared to lung the fibroblast cell culture (IMR90). The qPCR experiment performed on cell lines carried out in triplicate. (A) Wilcoxon test; (B) unpaired t-test); ${ }^{*} \mathrm{P}<0.05 ;{ }^{* * * *} \mathrm{P}<0.001$. NSCLC, non-small cell lung cancer.

A o

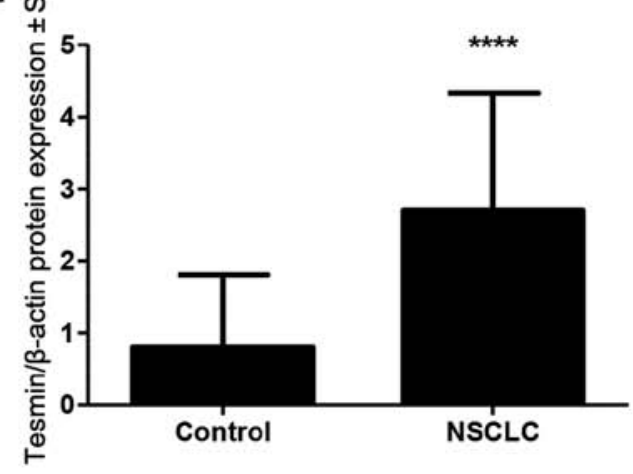

C

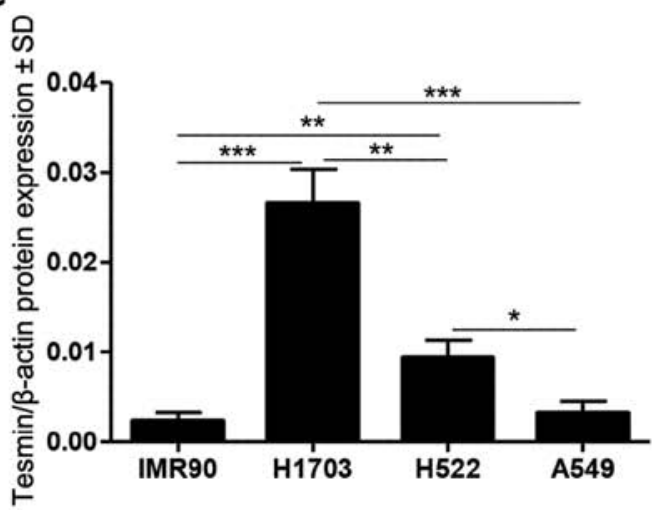

B

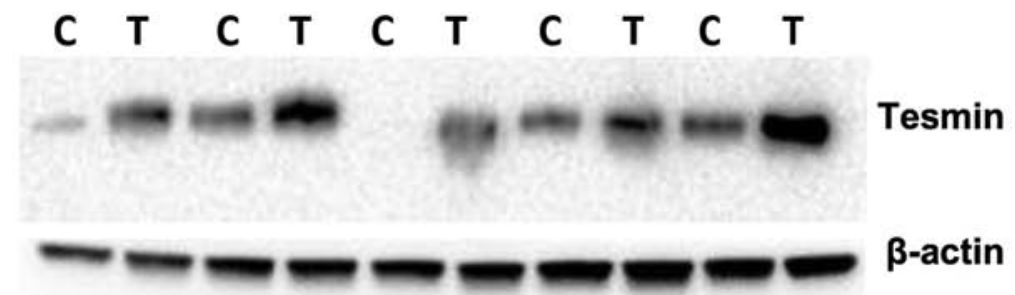

D

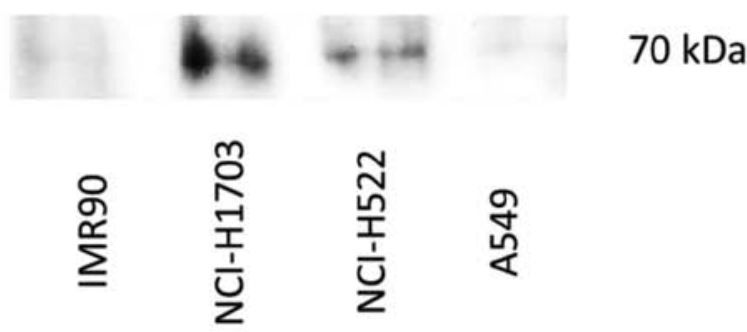

Figure 4. (A and B) Higher expression of tesmin protein was demonstrated in NSCLC specimens compared to that noted in paired non-malignant lung tissue specimens used as a control. (C and D) Higher tesmin protein expression was determined in the nuclear fraction of lung cancer cell lines compared to nuclear fraction of lung fibroblasts as evaluated by western blot analysis. The WB experiment performed on cell lines was carried out in triplicate. (A) Wilcoxon test; (C) Unpaired t-test). ${ }^{*} \mathrm{P}<0.05 ;{ }^{* *} \mathrm{P}<0.01 ;{ }^{* * * *} \mathrm{P}<0.001,{ }^{* * * *} \mathrm{P}<0.0001$. NSCLC, non-small cell lung cancer; $\mathrm{T}$, tumor tissue; $\mathrm{C}$, control tissue.

Fig. 6A). In the WB group higher expression of tesmin was also associated with shorter survival $(\mathrm{P}<0.05$, Mantel-Cox test; Fig. 6B). In addition, using Kaplan-Meier plotter software (31), higher MTL5 mRNA expression was associated with shorter survival time, especially in groups with a lower stage of cancer (malignant grade $\mathrm{G} 1$, and in stage 1 of the disease) (Fig. 6C-E).

\section{Discussion}

The present study was the first to demonstrate higher expression of tesmin (MTL5) in non-small cell lung cancer (NSCLC) cells compared to control tissue. The present study is the only one that describes in detail the presence of this protein in NSCLC. Expression of tesmin in NSCLC proves 


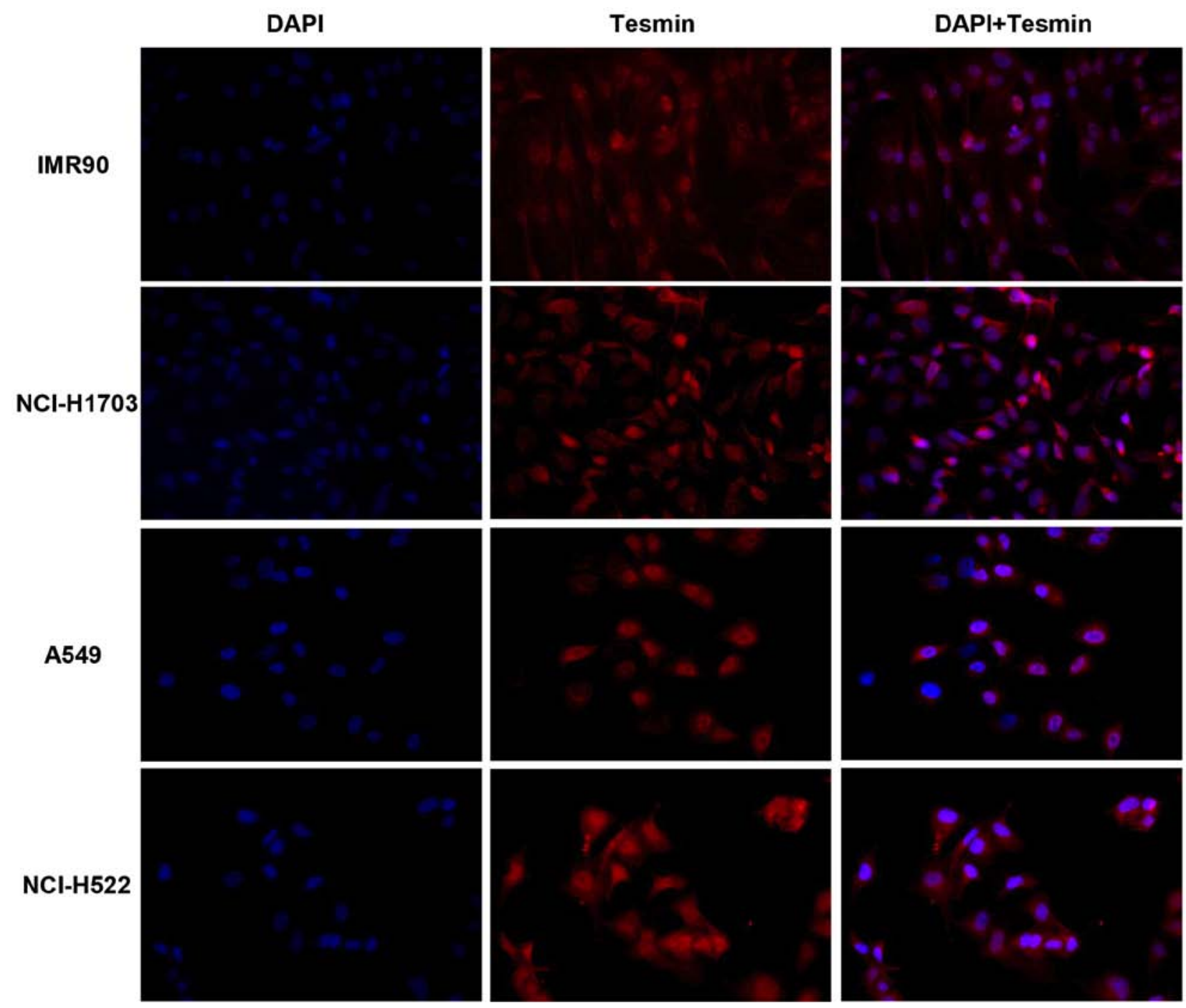

Figure 5. Localization of tesmin expression in the nuclei and cytoplasm in the control lung fibroblast cell culture (IMR90) and NSCLC cell lines (NCI-H1703, A549 and NCI-H522) obtained by immunofluorescence (IF). Magnification, x400. NSCLC, non-small cell lung cancer.

above all that the role of this protein is much more diverse than the regulation of meiotic division in germ cells or co-activation of the nuclear mineralocorticoid receptor (24).

The subcellular location of tesmin was studied in male and female germ cells and was dependent on the meiotic division stage. Before meiosis its expression was observed in the cytoplasm of germ cells whereas during meiosis it was translocated to the cell nucleus and then it was again located in the cytoplasm (18). In addition, oxidative stress was found to induce premature occurrence of nuclear expression of tesmin. The exact role of this protein in different cells is still unknown. The findings of this study confirmed the increased expression of tesmin in the cytoplasm and the nucleus of lung cancer cells compared to control tissue suggesting that tesmin may be related to the process of carcinogenesis in NSCLC. In addition, increased expression of this protein in cases with higher pT suggests its role in NSCLC progression.

Analysis of the overall survival of NSCLC patients showed worse prognosis in cases with higher tesmin expression compared to patients with low expression of the protein (Kaplan-Meier plotter and our own studies) indicating the influence of this protein in cancer development.
Similar observations have reported in the case of proteins from the metallothionein (MT) family in many different types of cancers. Functional similarity of these proteins with tesmin (regulation of heavy metal ion concentration, response to oxidative stress) may suggest a similar mechanism triggering overexpression of MTs and tesmin and a similar role in the process of carcinogenesis $(12,13)$. This hypothesis, however, requires further research.

Additionally, as in the case of MTs, we also found a positive correlation of tesmin expression with the Ki-67 proliferation antigen, suggesting the influence of tesmin on stimulation of NSCLC cell proliferation. Considering the previous reports on tesmin, including its relationship with the meiotic division of germ cells, this observation seems to be correct. Nevertheless, further studies are warranted (18).

The obtained immunofluorescence (IF) results based on tissue material were also confirmed by cell line studies in which tesmin expression was demonstrated in both the cytoplasm and the nucleus (IF).

Furthermore, as in the case of tissue sample studies, in squamous cell carcinoma and lung adenocarcinoma cell lines, in vitro experiments showed significantly higher expression of tesmin 
A
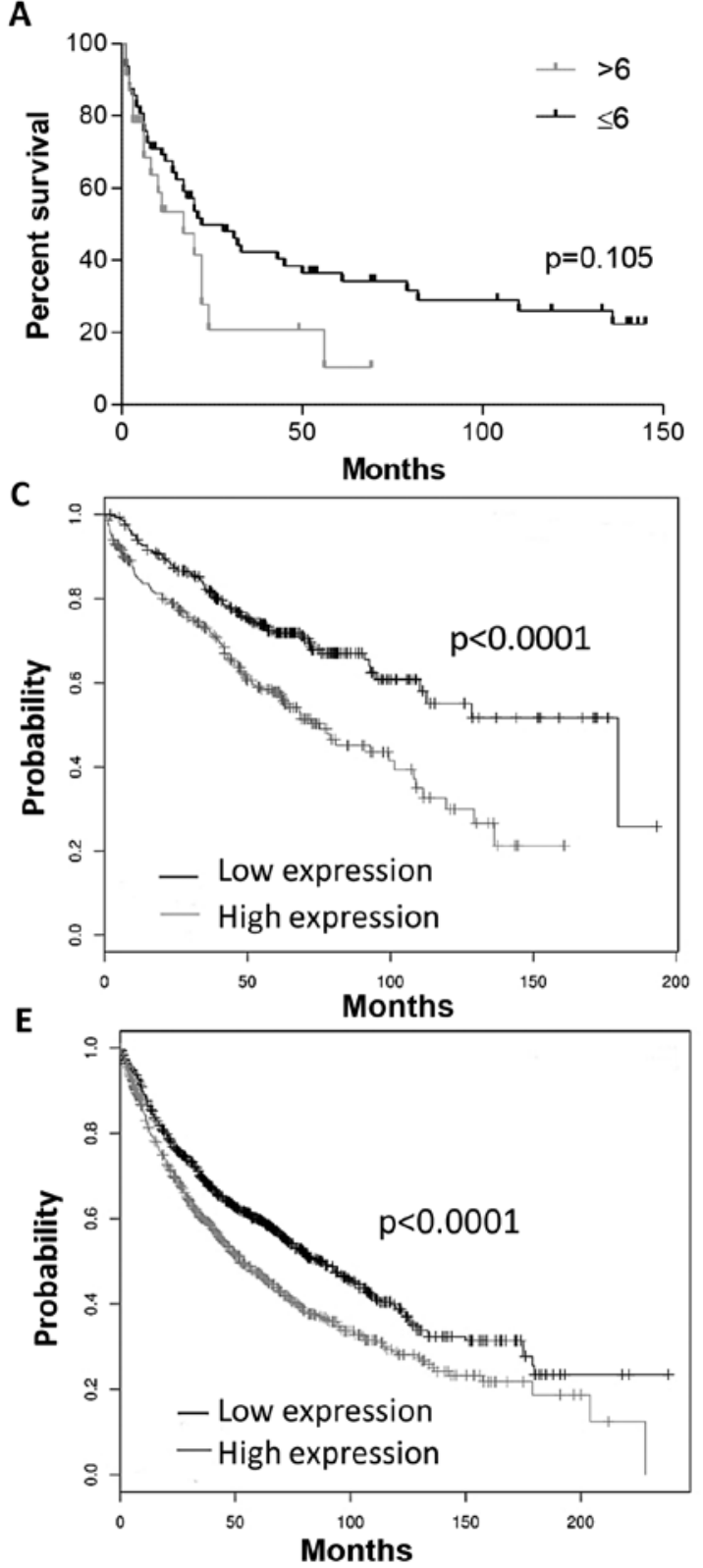

B
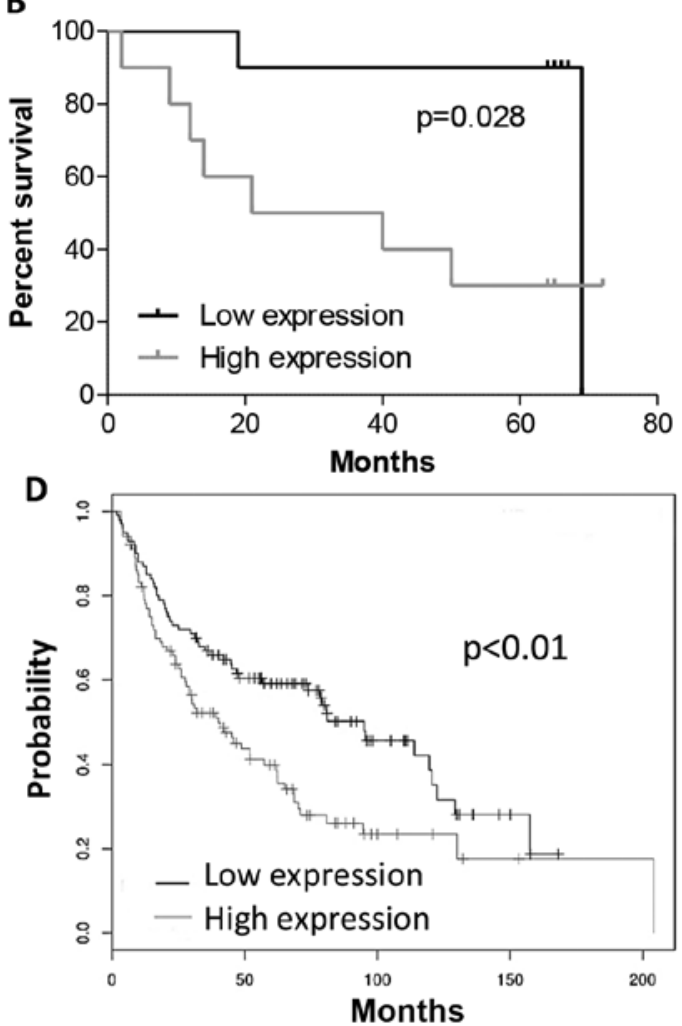

Figure 6. Analysis of the overall survival of NSCLC patients with high and low tesmin (A) IHC and (B) WB expression. Cancer patients with high- and low-gene expression for tesmin (cut-off point-median) and (C) histological grade G1, (D) clinical stage I and (E) all stages of the disease. The analysis (C-E) was performed using Kaplan-Meier plotter online software. NSCLC, non-small cell lung cancer.

(by western blotting) and MTL5 mRNA in relation to the control cell line (IMR90), which may additionally confirm the involvement of tesmin in the process of neoplastic transformation.

It seems useful to focus on translocation of tesmin from the cytoplasm to the nucleus during meiotic divisions and its relationship with the exposure of germ cells to increased concentration of heavy metal ions as reported by other authors (22). In our study, we also observed tesmin expression in both the cytoplasm and the nucleus. However, nuclear expression of tesmin was not related to the clinicopathological data of patients. Its potentially different role in the cell nucleus and the cytoplasm of lung cancer cells certainly requires further research.

\section{Acknowledgements}

Not applicable.

\section{Funding}

The present study was financed by the National Science Centre, Poland under the programme 'Preludium 12' project no 2016/23/N/NZ5/02570.

\section{Availability of data and materials}

The datasets used during the present study are available from the corresponding author upon reasonable request.

\section{Authors' contributions}

JG designed the study, evaluated the IHC reaction, prepared the database, performed the statistical analysis, analysed the results and created a draft of the manuscript; AG performed 
the $\mathrm{qPCR}$ analysis, prepared the database and analysed the results; MO and NGP prepared the in vivo WB analysis and all in vitro experiments, created the database and analysed the results; AP prepared the IHC analysis, created the database and analysed the results; KRW prepared the IF analysis and the in vitro experiments and analysed the results; $\mathrm{AR}$ obtained the in vivo material from patients, collected the clinical data of patients, prepared the database and analysed the results. PD, MPO and ZK supervised methodical all experiments, analysed the results, prepared, reviewed and edited the manuscript. All authors read and approved the manuscript and agree to be accountable for all aspects of the research in ensuring that the accuracy or integrity of any part of the work are appropriately investigated and resolved.

\section{Ethics approval and consent to participate}

The experiment was performed in accordance with the ethical standards and following approval of the Ethics Committee of Wroclaw Medical University (decision no. KB 455/2009 and KB 40/2017) and all patients provided a written statement of informed consent for the use of the material samples for scientific research.

\section{Patient consent for publication}

Not applicable.

\section{Competing interests}

The authors state that they have no competing interests.

\section{References}

1. Stewart BW and Wild CP (eds): Word Cancer Report 2014. World Health Organization, Lyon, 2014.

2. Didkowska J, Wojciechowska U and Olasek P: Zachorowania i zgony na nowotwory złośliwe w Polsce. Krajowy Rejestr Nowotworów, Centrum Onkologii-Instytut im. Marii Skłodowskiej-Curie. From: http://onkologia.org.pl/k/epidemiologia. Accessed July 06, 2018

3. Ferlay J, Soerjomataram I, Dikshit R, Eser S, Mathers C, Rebelo M, Parkin DM, Forman D and Bray F: Cancer incidence and mortality worldwide sources, methods and major patterns in GLOBOCAN 2012. Int J Cancer 136: E359-E386, 2015.

4. Krzakowski M, Jassem J, Dziadziuszko R, Kowalski DM, Olszewski W, Orłowski T, Rzyman W and Smorczewska M: Zalecenia postępowania diagnostyczno-terapeutycznego w nowotworach złośliwych-2013 r. Nowotwory płuca i opłucnej oraz śródpiersia, Via Medica 1: 69-101, Gdańsk, 2013.

5. Theocharis SE, Margeli AP and Koutselinis A: Metallothionein: A multifunctional protein from toxicity to cancer. Int J Biol Markers 18: 162-169, 2003.

6. Vašák M: Advances in metallothionein structure and functions. J Trace Elem Med Biol 19: 13-17, 2005.

7. WierzowieckaB,Gomulkiewicz A,Cwynar-ZajacL,OlbromskiM, Grzegrzolka J, Kobierzycki C, Podhorska-Okolow M and Dziegiel P: Expression of metallothionein and vascular endothelial growth factor isoforms in breast cancer cells. In Vivo 30: 271-278, 2016

8. Theocharis SE, Margeli AP, Klijanienko JT and Kouraklis GP: Metallothionein expression in human neoplasia. Histopathology 45: 103-118, 2004.
9. Romero-Isart $\mathrm{N}$ and Vašák $\mathrm{M}$ : Advances in the structure and chemistry of metallothioneins. J InOrg Biochem 88: 388-396, 2002.

10. Bay BH, Jin R, Huang J and Tan PH: Metallothionein as a prognostic biomarker in breast cancer. Exp Biol Med (Maywood) 231: 1516-1521, 2006.

11. Shimoda R, Achanzar WE, Qu W, Nagamine T, Takagi H, Mori M and Waalkes MP: Metallothionein is a potential negative regulator of apoptosis. Toxicol Sci 73: 294-300, 2003.

12. Cherian MG, Jayasurya A and Bay BH: Metallothioneins in human tumors and potential roles in carcinogenesis. Mutat Res 533: 201-209, 2003.

13. Dziegiel P, Pula B, Kobierzycki C, Stasiolek $M$ and Podhorska-Okolow M: Metallothioneins in normal and cancer cells. Adv Anat Embryol Cell Biol 218: 1-117, 2016.

14. Werynska B, Pula B, Kobierzycki C, Dziegiel P and Podhorska-Okolow M: Metallothioneins in the lung cancer. Folia Histochem Cytobiol 53: 1-10, 2015.

15. Ostrakhovitch EA, Olsson PE, Jiang S and Cherian MG: Interaction of metallothionein with tumor suppressor $\mathrm{p} 53$ protein. FEBS Letters 580: 1235-1238, 2006.

16. Ostrakhovitch EA, Olsson PE, von Hofsten J and Cherian MG: P53 mediated regulation of metallothionein transcription in breast cancer cells. J Cell Biochem 102: 1571-1583, 2007.

17. Coyle P, Philcox JC, Carey LC and Rofe AM: Metallothionein: The multipurpose protein. Cell Mol Life Sci 59: 627-647, 2002.

18. Sutou S, Miwa K, Matsuura T, Kawasaki Y, Ohinata Y and Mitsui Y: Native tesmin is a 60-kilodalton protein that undergoes dynamic changes in its localization during spermatogenesis in mice. Biol Reprod 68: 1861-1869, 2003.

19. HUGO Gene Nomenclature Comitte. http://www.genenames.org. Accessed June 1, 2018.

20. Sugihara T, Wadhwa R, Kaul SC and Mitsui Y: A novel testis-specific metallothionein-like protein, tesmin, is an early marker of male germ cell differentiation. Genomics 57: 130-136, 1999.

21. Olesen C, Møller M and Byskov AG: Tesmin transcription is regulated differently during male and female meiosis. Mol Reprod Dev 67: 116-126, 2004.

22. Matsuura T, Kawasaki Y, Miwa K, Sutou S, Ohinata Y, Yoshida F and Mitsui Y: Germ cell-specific nucleocytoplasmic shuttling protein, tesmin, responsive to heavy metal stress in mouse testes. J Inorg Biochem 88: 183-191, 2002.

23. Maremanda KP, Khan S and Jene G: Zinc protects cyclophosphamide-induced testicular damage in rat: Involvement of metallothionein, tesmin and Nrf2. Biochem Biophys Res Commun 445: 591-596, 2014.

24. Rogerson FM, Yao YZ, Young MJ and Fuller PJ: Identification and characterization of a ligand-selective mineralocorticoid receptor coactivator. FASEB J 28: 4200-4210, 2014.

25. Fic M, Pula B, Rogala K and Dziegiel P: Role of metallothionein expression in gastrointestinal cancers. Postępy Biol Komórki 40: 5-20, 2013.

26. Oh JH, Yang JO, Hahn Y, Kim MR, Byun SS, Jeon YJ, Kim JM, Song KS, Noh SM, Kim S, et al: Transcriptome analysis of human gastric cancer. Mamm Genome 16: 942-954, 2005.

27. Penney KL, Sinnott JA, Tyekucheva S, Gerke T, Shui IM, Kraft P, Sesso HD, Freedman ML, Loda M, Mucci LA and Stampfer MJ: Association of prostate cancer risk variants with gene expression in normal and tumor tissue. Cancer Epidemiol Biomarkers Prev 24: 255-260, 2015.

28. Remmele W and Stegner HE: Recommendation for uniform definition of an immunoreactive score (IRS) for immunohistochemical estrogen receptor detection (ER-ICA) in breast cancer tissue. Pathologe (German) 8: 138-140, 1987.

29. Livak KJ and Schmittgen TD: Analysis of relative gene expression data using real-time quantitative PCR and the $2^{-\Delta \Delta \mathrm{Ct}}$ method. Methods 25: 402-408, 2001.

30. Laemmli UK: Cleavage of structural proteins during the assembly of the head of bacteriophage T4. Nature 227: 680-685, 1970.

31. Győrffy B, Surowiak P, Budczies J and Lánczky A: Online survival analysis software to assess the prognostic value of biomarkers using transcriptomic data in non-small-cell lung cancer. PLoS One 8: e82241, 2013. 